\title{
KIBRIS SORUNUNUN ULUSLARARASI HUKUK AÇISINDAN DEĞERLENDİRILMESI
}

\author{
Prof. Dr. A. Füsun ARSAVA*
}

\begin{abstract}
Güney Kıbrıs Rum yönetimi 4 Temmuz 1990'da Avrupa Birliği'ne tam üyelik başvurusu yaptı. Bu başvuru ile birlikte, başvurunun hangi devlet adına yapıldığı, dolayısıyla 1960 yılında kurulan Kıbrıs devletinin mevcudiyetinin devam edip etmediği tartışmaları gündeme geldi. 1960 yılında uluslararası camiaya bağımsız bir devlet olarak katılan Kıbrıs Cumhuriyeti kuruluş yıllarındaki koşullar itibariyle uluslararası ve ulusal uzlaşıya istinaden ortaya çıkmış bir devlettir ${ }^{1}$.
\end{abstract}

Kıbrıs sorunu uluslararası barışı tehdit eden bir konu ${ }^{2}$ olarak o dönemde bir taraftan sömürgeci devlet olarak Ingiltere'yi, diğer taraftan Lozan anlaşması ile bırakılmış, Türk toplumunun yaşadağı bir toprak olarak Türkiye'yi (bknz. Lozan anl. 16. md.) ve Rum toplumunun yaşadığı bir toprak olarak Yunanistan'ı ilgilendirmekteydi. Uluslararası barışı tehdit eden soruna taraf olan söz konusu devletler 1959-1960 da Zürih ve Londra'da bir araya gelerek yaptıklan anlaşma ${ }^{3}$ ile adanın taraf devletlerden birinin egemenliğinde kalması veya bőlünmesi yahut bir devlete katılması yerine bağımsız bir devlet olarak uluslararası camiaya katılmasını ve bu katılmanın koşullarını kabul ettiler ${ }^{4}$.

Zürih ve Londra anlaşmasında ortaya konulan bu koşullar, anlaşmalar ile kurulan Kıbris Cumhuriyeti tarafından nihai anlaşmalarda kabul edildi ve Garanti anlaşmasında somutlaştırıldı. Ingiltere, Türkiye, Yunanistan ve Kıbrıs Cumhuriyeti'nin taraf olduğu Garanti anlaşması uluslararası uzlaşının sonucu olarak Kıbrıs devletinin bağımsızlığını,

\footnotetext{
*A.U. Siyasal Bilgiler Fakültesi, Oğretim Uyesi.

${ }^{1}$ Uzlaşı sonucu ortaya çıkmış devlet örnekleri için bkz: A. Verdross, Völkerrecht, Wien 1959. s. 125 vd.

${ }^{2}$ Kıbrıs uluslararası barışı tehdit eden bir konu olarak 1954 yılından itibaren 1955, 1956. 1957 ve 1958'de BM Genel Kurulu'nun gündeminde yer almıştır.

${ }^{3}$ Anlaşma metni için bkz: L. Dischler, Die Zypernfrage, Frankfurt a. M., Berlin 1960.

${ }^{4}$ P. Tzermias, "Die Entstehung der Republik Zypern", bkz: Jahrbuch des öfentlichen Rechts, Bd. 9 (1960), s. 252.
} 
ülkesel bütünlügünü ve güvenliğini garanti konusu olarak teminat altına alırken, ulusal uzlaşının ifadesi olarak anayasanın temel hükümlerini teminat altına almıştır. Garanti konularının yer aldığ 2 2. madde bu çerçevede Kıbns Cumhuriyeti'nin bir devlet ile siyasi ve ekonomik birliğe girmesini yasaklarken, aynı paralelde Kıbrıs Cumhuriyeti'nin bir başka devlete katılmasını ve taksimini de yasaklamıştır.

Kıbrıs sorunu Kıbns Anayasası'nın temel hükümlerinin ihlali nedeniyle 1963 yılında yeniden uluslararası platforma gelmiştir.

Kıbrıs Cumhuriyeti anayasası ulusal uzlaşıyı, sayısal verilerden uzak bir anlayıs içinde, her iki ulusal grubun genel iradeyi birlikte belirleme hakkını kabul ederek ve bunları deģiştirilmesi mümkün olmayan temel (fundamental) hükümler olarak ilan ederek sağlamışt1 5 .

Anayasanın temel hükümleri içinde mütalaa edilmesi nedeniyle Garanti anlaşmasının teminatı kapsamına giren Türk toplumunun birlikte belirleme hakkının ihlali bir taraftan ulusal banı̧ı, diğer taraftan da uluslararası barışı bozmuştur. Heterojen karakterli toplumlarda birlikte belirleme hakkı toplumsal uzlaşının onkoşuludur. ZürihLondra gőrüşmelerinde de radikal olarak selfdetermination iddialarının dikkate alınması halinde bütünlüğ̈ün korunamayacağı anlaşılmıştır. Bütünlüğün ve birliğin korunması adına bir uzlaşı sağlanmış, ulusal gruplann hepsine büyüklüklerinden bağımsız olarak anlaşmalarda genel iradeye katılma olanağı yaratılmıştır. Çok uluslu yapılarda birbirine ters düsen selfdetermination iddiaları uzlaştırıldığı nispette devletlerin varlığı temin edilir. Bu nedenle Zürih-Londra ąnlaşmasında ulusal bir devlet değil, iki uluslu bir devlet yaratma amacı kabul görmüştür6

Heterojen toplumlarda genel iradenin sadece çogunluk tarafından belirlenmesi, sayısal olarak azınlıkta olan ulusal grubun safdışı edilmesi, çok uluslu toplumları parçalanmaya götürïr ${ }^{7}$. Çok uluslu bir insan topluluğuna ortak yaşam bilinci çoğunluk prensibine istinadın kazandırılamaz. Demokrasinin temel prensibi olan çoğunluk prensibi, çok uluslu toplumlarda genel iradenin belirlenmesinde şans eşitliğini sağlayamaması nedeniyle farklı unsurları birleştirici değil, bölücü sonuçlar doğurur. İşte bu nedenle Kibris Cumhuriyeti anayasası her iki ulusal grubun genel iradeye nisbi anlamda katılımını, bu şekilde ortak yaşam çıkarlarının korunmasını kabul etmiştir. Adada Rumların çoğunluğu teşkil etmesi nedeniyle, Türk toplumunun birlikte belirleme hakkının Rum toplumunun selfdetermination hakkını ihlal ettiği iddiası, çok uluslu devlet anlayışından ulușal devlet anlayışına yeniden dönüştür. Oysa Garanti anlaşması

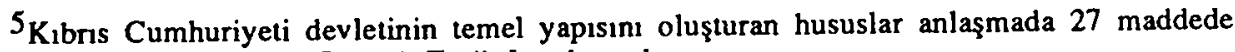
düzenlenmiştir. Bkz: Doc. A Zürih-Londra anlaşması.

${ }^{6}$ H. Wilhelmy, Zypern. Bkz: Handwörterbuch des Soziaalwissenschaften, Bd. 12 (1965), s. 506 .

${ }^{7} \mathrm{~T}$. Fleiner, Die Kleinstaaten in den Staatenverbindungen des 20. Jchrhunderts, Zurich 1966, s. 299; T. B. Balta, "Das Selbstbestimmungsrecht der Bevölkerung ethnisch inhomogener Gebiete", bkz: Ausgewaehlte Gegenwartsfragen zum Problem der Verwirklichung des Selbstbestimmungsrechts der Völker, Bd. II Manchen 1964/65 s. 17 vd. 
Kıbrıs Cumhuriyeti devletine bu anlamda bir anayasa muhtariyeti tanımamışur ${ }^{8}$. Tamamen tersine devletin selfdetermination hakkına getirilen sınırlama ulusal grup haklarının teminatı olarak kabul edilmiştir ${ }^{9}$. Normal koşullarda bir devletin selfdetermination hakkının sinırlanması halkının selfdetermination hakkının sınırlanması sonucunu verirken, homojen insan topluluğu olmayan devletlerde devletin selfdetermination hakkının sinırlanması bir ulusal grubun yahut halkın selfdetermination hakkının teminatı olmaktadır. Kıbrıs orneğinde de devletin selfdetermination hakkının sınırlanması ulusal gruplar arasında denge yaratılmasının bir teminatı olmuştur. Garanti anlaşmasının ve bu paralelde anayasanın iradesi, devletin bir ulusal grubun çıkarlarının temsilcisi olmasının engellenmesidir. Rum toplumunun, daha sonra Rum yőnetiminin kendi iradesini Kıbris Cumhuriyeti devletinin iradesi olarak geçerli kılma iddiası Garanti anlaşmasının ve anayasanın esasen engellemek istediği husustur.

Türk toplumunun birlikte belirieme hakkı dışında, Rum toplumunun selfdetermination hakkına ters düştügüunü iddia ettiŏ̉i diğer hususlar Birleşmiş Milletler Güvenlik Konseyini 1963 yılında uzun süre meşgul etmiştir ${ }^{10}$. Konu Güvenlik Konseyine Garanti anlaşmasının hükümsüzlüğüne karar verme talebi ile getirilmiştir. Ancak bir anlaşma yine anlaşmanın taraflannca ortadan kaldırılabilir yahut değiş̧irilebilir. Kaldı ki Garanti anlaşması sürekli bir karaktere sahiptir; tek tarafı olarak da anlaşmanın feshi mümkün değildir ${ }^{11}$. Anlaşmada ayrıca anlaşmayı sona erdiren sebepler yer almamaktadır ${ }^{12}$. Güvenlik Konseyi bu prensipten hareketle, Garanti anlaşmasının geçerliliğine ve sorunun barış̧ı yöntemlerle çözümlenmesine ve bir $\mathrm{BM}$ banş gücünün Kıbrı'a görderilmesine karar vermiştir ${ }^{13} .1960$ Garanti Anlaşması anlaşmada garantơr olarak yer alan devletler arasında dengelerin kurulduğu bir anlaşmadır. Bu anlaşma bizatihi Kıbrıs Cumhuriyeti devletinin çıkarlarının korunması yanısıra garantơr devletlerin uluslararası çıkarlarını uzlaşuran bir anlaşmadır. Garanti anlaşmasının hükümlerinin anayasanın temel hükümleri olarak kabul edilmesi nedeniyle, Garanti anlaşmasının ihlali sadece bir uluslararası hukuk ihlali olarak ortaya çıkmamakta aynı zamanda bir anayasa ihlali olarak ortaya çıkmaktadır. Garanti anlaşması garanti objelerini sadece 3. devletlere karşı değil, Kıbrns cumhuriyeti devletinin kendisine karşı koruma altına almıştır. Bu nedenle garantör devletlerin yaratılan hukuk düzeninin Kıbris Cumhuriyeti tarafindan ihlal edildiği nispette müdahale hakkı doğmakıadır ${ }^{14}$.

${ }^{8}$ P. Tzermias, "Die Verfassung der Rebuplik Zypern", bkz: Jahrbuch des öfentlichen Rechts, Bd. 10 (1961), s. 485-525.

${ }^{9}$ P. Tzermias, "Die Entstehung der Rebuplik Zypern", bkz: Jahrbuch des öfentlichen Rechts, Bd. 9 (1960), s. 245-295.

${ }^{10}$ Konu BM Guvenlik Konseyi'ne ilk kez 27.12.1963'de gelmiştir. Bkz: O. Leichter, "Zypernkrise vor den Vercinten Nationen", bkz: Zeitschrift für VN und ihre Sonderorganisationen, (April .1964), s. 41 vd.; C. Heinze, "Zypern, eine Aufgabe fur Athen und Ankara", Aussenpolitik, (Oktober 1966), s. 624-635.

${ }^{11} \mathrm{H}$. Zietschmann, Die völkerrechtliche Garantie seit den LocarnoVertraegen, Berlin 1938, s. 7.

12 N. Karagil, Kıbrıs Meselesi Üzerinde Son Konuşmalar ve Yankılar, Istanbul 1964, s. 117.

13 UN Doc. S/5575 (1964).

${ }^{14} \mathrm{Bir}$ devletin kendi yurttaşlarına nasıl muamele ettiği hususu artık ulusal yetki alanında kalmamaktadır. Insani müdahale günümüzde bu çerçevede ortaya çıłkmaktadır. Türkiye'nin 
Kıbrıs devletinin iradesine ters düşen bir müdahalenin BM anlaşmasının kuvvet kullanmayı yasaklayan 2. madde 4. fikrasına ters düştüğü, Garanti anlaşmasında öngörülen bu düzenlemenin BM anlaşmasının 103. maddesi ışı̆̆ında hüküm ve sonuç doğuramayacă̆ı iddiasına, Uluslararası Hukukun ağırlıklı olarak esnek hukuk (dispositiv) normlarından oluştuğu ve devletleri kendi iradesi ile (anlaşmalarla) egemenliklerine sinırlamalar yapabildikleri yanıtı verilmektedir.

Meşru olmayan bir müdahalede ayırıcı özellik karşı iradedir. "Karşı irade" Kıbrıs Cumhuriyeti Devleti'nin Garanti anlaşmasında bir taraf olduğu gerçç̆i karşısında iddia edilemez. BM anlaşması BM'e üye olan devletlerin toprak bütünlügüne veya siyasi bağımsızlığına karşı kuvvet kullanılmasını ve kuvvet kullanma tehdidinde bulunmayı yasaklamıştır. Kıbrıs Garanti anlaşması tamamen aynı paralelde Kıbrıs Cumhuriyetinin toprak bütünlügüüü, bağımsızlığını temin etmek amacı ile bir müdahale hakkı kabul etmiştir. Kıbrıs Cumhuriyetinin bağımsızlığını, toprak bütünlüğünü koruma amacı ile, bu amaca matuf araç (müdahale) arasında tenakuz değil, paralellik vardır.

Bir devletin bağımsızlığının garanti edilmesi 1960 Garanti Anlaşmasına ơzgü bir model değildir. Konu Milletler Cemiyeti döneminde Alman-Avusturya Gümrük Birliği projesi nedeniyle 1931'de Sürekli Adalet Divanı'nın gündemine gelmiştir. Sürckli Adalet Divanı verdiği istişari mütalaa ile oluşturulacak gümrük birliğinin Avusturya devletinin bağımsızlığını garanti eden 1919 tarihli St. Germain ve 1922 tarihli Cenevre protokolüne ters düşüp düşmediğini ortaya koymuştur ${ }^{15}$.

Bağımsızlığın hukuki ve siyasi boyutu prensip olarak bir arada mütalaa edilmemektedir ${ }^{16}$. Ekonomik bir anlaşma devletin uluslararası hukuk statüsünde değişiklik yaratmaz; siyasi bağımsızlık fiili güç ilişkisini ifade eder. Çağdaş Uluslararası Hukuk egemenliğin bölünebileceğini kabul etmektedir. Hukuki ve siyasi bağımsızlığın bir arada bulunmaması mümkündür. Bir devlet iç egemenliğe sahip iken, dış egemenliğe sahip olmayabilir. Siyasi bağımsızlık, egemenlik için aruk bir ölçü değildir. Bugün egemen olarak nitelenen birçok devletin siyasi bağımsızlığı yoktur ${ }^{17}$. Uluslarerası Hukuk günümüże bağımsızlığın siyasi bağımsızlık sınırlamalarına rağmen özünde devam edebileceğini kabul etmektedir. Ancak bir Avusturya yahut Kıbris örneğinde

1974 yılında yapmış olduğu mưdahalenin Garanti anlaşmasında yer alan dayanağı dışında soydaşlarının insan hakları ihlallerine son verilmesi gerekçesine de dayandırılması mümkündür. Bkz: U. Denecke, Die humanitaere Intervention und ihr Verhaeltnis zum Rechtsschutzsystem der europaeischen Menschenrechtskonvantion. Würzburg 1972, s. 66; L. Blesinger, Die sogenannte vereinbarte und erbetene Intervention, Bonn 1966, s. $128 \mathrm{vd}$.

15 Bkz: PCIJ Series, A/B, Nr. 41.; Çekoslovakya ve Fransa, Cenevre protokolünün St. Germain anlaşmasından farkhı olarak Avusturya'nın siyasi bağımsızlığını da garanti altına aldığını, bağımsızlığın korunması mükellefiyetinin, siyasi ve ekonomik bağımsızlığı sınırlayan özel anlaşma ilişkilerine girmemeyi gerektirdiğini iddia etmiştir. Bu yaklaşıma göre fiili bağımsızlığın ihlali Cenevre protokolüne ters düşmektedir. Bkz.: Archiv der Gegenwart 1931/32, s. 18 c.

16 D. W. Gunst, Der Begriff der Souveraenitaet im modernen Völkerrecht, Berlin 1953, s. 114 vd.; H. G. Koppensteiner, Die europaeische Integration und das Souveraenitaetsproblem, Baden-Baden, Bonn 1959, s. 49.

${ }^{17}$ G. Dahm, Völkerrecht Bd. I, s. 155 vd., Stuttgart 1958. 
görüldügü gibi, hukuki bağımsızlığın korunması mükellefiyetinin, tamamen veya kısmen siyasi veya ekonomik bir birliğe katılmama mükellefiyeti ile teminat altına alınması mümkündür ${ }^{18}$. Kıbrıs ${ }^{-G a r a n t i ~ a n l a s ̧ m a s ı ~ A v u s t u r y a ~ i l e ~ z a m a n ı n d a ~ y a p ı l a n ~}$ Cenevre protokolünde olduğu gibi, hukuki bağımsızlığı siyasi bağımsızlıkla temin etmek istemiştir. Garanti anlaşmasında diğer bir ifadeyle siyasi bağımlılığın hukuki bağımsızlığın ortadan kalkmasına neden olabileceği varsayılmışur.

Siyasi bağımsıżlığı sınırlayan anlaşmaların hukuki bağımsızlığı ihlal edip etmediği hususu da tarışma konusu olmuştur ${ }^{19}$. Çăgdaş Uluslararası Hukukda hukuki bağımsızlı̆̆ı negatif garanti ile, diğer bir ifade ile siyasi yahut ekonomik bir birliğe katılma yasağı ile teminat altına alma geleneği bulunmaktadır. Benzer hükümler 1955 yılında Avusturya ile akdedilen anlaşmada da bulunmaktadır ${ }^{20}$. Çăgđaş Uluslararası Hukuk, Uluslararası Hukuktan bağımsız olmayı değil, başka devletlerin iradesiden bağımsız olmayı bağımsızlık kriteri olarak kabul etmektedir. Garanti anlaşması ile üstlenilen egemenlik sınırlaması uluslararası barış adına kabul edilmiştir. Kıbrıs'ın tarafsız devlet modeli, Kıbrıs'ı siyasi gerilimlerden uzak tutma isteği sonucu doğmuştur.

Iıtifak anlaşması da Garanti anlaşmasını tamamlar bir şekilde Kıbrıs'ın bağımsızlık ve toprak bütünlüğünün korunmasına matuf olarak kollektif bir işbirliğini öngörmektedir. Garanti anlaşmasında garanti objeleri olarak karşımıza çıkan hususlar bu kez Ittifak anlaşmasında karşımıza çıkmaktadır. Bu durum iki anlaşmanın birbirine bağlılığını ortaya koymakiadır. Ittifak anlaşması sadece Kıbrıs lehine olarak, onun bağımsızlığının veya toprak bütünlüğünün doğrudan veya dolaylı olarak saldınıa uğramasına karşı akit taraflara yükümlülük getirmektedir (İngiltere Ittifak anlaşmasına taraf değildir). Anlaşma karşilıklılık esasına istinat etmemektedir.

Savunma nitelikli bir anlaşma olarak ittifak anlaşması BM anlaşmasının hem yasal savunma ile ilgili 51. maddesinin hem de bölgesel savunma örgütleriyle ilgili 53 . maddesinin özelliklerini taşımaktadır 21 .

Kıbrıs Cumhuriyeti devletinin iç selfdetermination hakkının sınırlandırılması, ulusal gruplar arasında dengeyi (ulusal grup çauş̧malarını önlemek için) temin için bulunan bir formülken, Kıbrıs Cumhuriyeti devletinin dış selfdetermination hakkının sınırlandırılması, garantör devletlerin çıkarlarının bağdaşırılması için bulunan bir formüldür 22 .

${ }^{18}$ Sürckli Adalet Divanı, Cenevre protokolünün hukuki bağımsızh̆ğı siyasi bağımsızlık mükellefiyeti ile teminat altına aldığı şeklinde bir görüş oluşturmuştur. Avusturya ve Almanya arasında Gümrük Birliği projesinden bu görüşün verilmesinden önce vazgeçilmiştir.

19 P. Tzermias, "Der neue Status Zyperns", Archiv des öfentlichen Rechts, Bd. 84 (1959), s. 459-489.

$20 \mathrm{G}$. Ot, Die internationale stellung österreichs, vor und nach dem Staatsvertrag. Würzburg 1970 , s. 100.

${ }^{21}$ Ittifak anlaşmaları organize işbirliği olmaması nedeniyle prensip olarak organlar oluşturmaz. Ancak Kıbrıs örneğinde tavsiye ve danışma niteliğinde karar veren organlar kurulmuştur.

22 Bkz: A. Füsun Beşler (Arsava), Die völkerrechtliche Lage Zyperns unter besonderer Berücksichtigung des Selbstbestimmungsrechts, s. 53 vd., s. 
Zürih-Londra anlaşmasında Kıbrıs Cumhuriyeti devletinin iç ve dış selfdetermination hakkına getirilen sınırlama Birleşmiş Milletler anlaşmasında dekolonizasyon için özel bir prosedür öngörülmemiş olması nedeniyle uluslararası Hukuka uygun kabul edilmektedir. Kıbrıs, sömürgeci devletin ve soruna taraf olan diğer devletlerin ongörmüş olduğu koşullarla uluslararası camiaya bir devlet olarak katılmıştır ${ }^{23}$.

Barış içinde birlikte yaşama prensibi adına Kıbrıs için bulunan formül, Kıbrıs Rum toplumunun Türk toplumunun birlikte belirleme hakkını reddetmesi ile işlerliğini yitirmiştir. Birlikte belirleme hakkı bu formül içinde, Kıbrıs devletinin kendine özgü, orjinal bir insan topluluğu olmaması, diğer bir ifade ile Kıbrıs devletinin insan topluluğunun başka devletlerin insan topluluklarının parçalarından oluşturulması nedeniyle tartı̧ılmaz bir ơnemi ve onceliği bulunmaktaydi. Farklı insan toplumlanndan devleti oluşturan bir insan top̀luluğu yaratılmasında birlikte belirleme hakkından katalizör bir rol beklenir ${ }^{24}$. Devleti oluşturan insan topluluğunu oluşturan unsurlar objektif ölçuler itibariyle farklılıklar gősterebilir. Onemli olan subjektif unsurun yaratılması, farklı insan toplumları arasında aynı devlete aidiyet bağının kurulması, bu farklı unsurlann aynı gemide yolculuk eden yolcular gibi kendilerini hissedip bir kader topluluğu oluşturmasıdır. Iş̧te bu oluşumu sağlayan araç birlikte belirleme hakkıdır; "one man one vote" prensibi değil, "one community one vote" prensibi beraberliği sağlayacaktur.

Rum toplumu ulusal devlet anlayışını bertaraf eden anlaşmalara ve anayasaya ters olarak yeniden ulusal devlet yaratma girişimine başlamıs, genel iradenin hakim toplum olarak Rumlar tarafından belirleneceğini ve Türk toplumunun en fazlasından azınlık olarak mütalaa edilebileceğini iddia etmiştir. Birleştirici bir unsur olan birlikte belirleme hakkının terkedilmesi, çoğunluk prensibinin benimsenmesi, iki uluslu bir devletin ulusal bir devlete dönüştürülmesi sonucunu doğurur ${ }^{25}$. Çoğunluk prensibi bir toprağın, ozellikle heterojen karakterli bir insan toplulugunun ikamet ettiği toprağın kaderinin tayininde tek başına dikkate alınması gerekli bir faktör değildir ${ }^{26}$. Stratejik noktai nazar, tarihsel bağlar, birlikteliği koruma iradesi çoğu kez çoğunluk prensibini uygulama dıṣı bırakır. Kıbris Türk toplumu sadece sayısal verilerden hareket ederek 400 yılı aşkın bir süredir yaşadığı, vatanı olan topraklarda azınlık statüsüni kabul etmek durumunda mıdır?

62; L. Blesinger, Die sogenannte vereinbarte und erbetene Intervention, Bonn 1966, s. 262; M. Woodhause, "Das Zypernproblem und die Abkommen von 1959", Europa Archiv 3 (1969), s. 74 vd.

${ }^{23}$ Selfdetermination hakkı devlete karşı yöneltilen bir iddiadır. Halkın iradesi ve devletin iradesi koloni toplumlarında birbirine ters düşer. Selfdetermination hakkını bu anlamda Kıbrıs halkı 1960 yılında Ingiltere'ye karşı ortak olarak kullanmıştır. Bkz.: P. Fahrni. Die Assozlation von Staaten mit anderen Staaten, Zürih 1967, s. 35.

${ }^{24} \mathrm{C}$. Heinze, "Zypern, eine Aufgabe für Athen und Ankara," Aussenpolitik, (Oktober 1966), s. 629.

$25 \mathrm{~J}$. Gaitanides, "Immer wieder Zypern" bkz: Zeltschrift für dle VN und ihre Sonderorganisationen (Dezember 1967) s. 555-556 makalesinde daha o tarihlerde Kıbris Rumlannın Yunanistan'a katılmak yerine adada ulusal bir devlet istediklerine işaret etmiştir.

${ }^{26}$ Stratejik noktai nazar ömeğin, Batı-Trakya, Aaland adalan, Güney Tirol sorununda ön plana çıkmıştır. Ornekler için bkz: H. Raschhofer, Selbstbestimmungsrecht und Völkerbund, Köln, 1969, s. 42. 
Kıbrıs Rum toplumu kendini Kıbrıs'ta ne ollçüde anavatanında kabul ediyorsa, Kıbns Türk topyumu da anavatanındadır. $O$ topluluğu oluşturan insanların sayısı değil, topluluğun niteliği onemlidir. Sayısal azınlık olmak, nitelikte "minus" statüyü beraberinde getirmez.

Azınlık statüsü insan haklan tabiatıdır; bireysal haklar temin eder. Azınlık kendi ozelliklerinin temini ile ilgilenir; genelde çoğunluğun yơnetimini kabul eder ${ }^{27}$. Oysa ulusal grup statüsü ulusal grubun genel iradeye katılımını sağlar. Zira ulusal grup kendini geçerli kılma iddiasındadır. Bu iddialar birlikte belirleme hakkı ile bağdaşunlır. Tüm ulusal grupların aynı iddiayı (geçerli olma) ileri sürdüğü bir ortamda devletin birliği adına ulusal grup statüsü en iyi çözümdür. Ulusal grup statüsü, ulusal grubun kimliğini korumasına ve geliştirmesine matuftur. 1960 Kıbris anayasası bu paralelde ulusal gruplann genel iradeye nispi katılımını kabul etmek yanısıra, her bir ulusal grubun kendi tüzel kişilği olan özerk bir yönetim biçiminde orgütlenmesini de kabul etmiştir ${ }^{28}$.

Bu ozerk yőnetim coğrafi esasa göre değil, kişisel ozzelliklere göre kabul edilmiştir. Özerk yönetim yasama, yürütme ve yargı alanında karşımıza çıkmaktadır. Bu alanlarda devlet yetkileri özerk yơnetime delege edilmiştir ${ }^{29}$.

Kıbris Tïrk toplumunun anayasada ongörülen ve Garanti anlaşmasında teminat alına alınan (anayasanın fundàmental hükümleri çerçevesinde) birlikte belirleme hakkından soyutlanması, onların bir federal devlet oluşturulması beklentisiyle selfdetermination hakkına istinaden once bir Kıbns Türk Federe devletinin ilanına ${ }^{30}$, arkasından 1983'de bağımsız Kuzey Kıbrıs Türk Devleti'nin ilanına zemin hazırlamıştır ${ }^{31}$.

Selfdetermination hakkı egemen ve bağımsız bir devleti parçalamak için kullanılamaz. Ancak BM genel kurulunun 1970 tarih ve 2625 (XXV) sayılı kararında belirtildiği gibi insan haklarına saygılı, genel iradede tüm halkın hakça temsilini temin eden bir devleti yıkmak veya parçalamak için kullanılamayan bu hak, bu ilkeleri çiğneyen

${ }^{27} \mathrm{H}$. Wilhelm, MInderheitenfrage/Völkerrecht/Europa: Grundsaetzliche Minderheltenfragen und Minderheitenfragen in Europe, Dokumentarische Berichte und Chronik für Unterricht und Studium, München 1977, s. 84-107.

28 Ulusal muhtariyet din, kultür, eğitim, okul, kişisel statü, spor dernekleri, hayır kurumlan, kooperatifçilik, kredi kurumlan alanlarını kapsamaktadır. Ulusal muhtariyet alanlarında ulusal grupların kendilerini etnik olarak bağlı hissettikleri devletlerle işbirliği yapabilmesi kabul edilmiştir.

${ }^{29}$ Türk toplumunun genel iradeye katılımı engellendiği gibi, ulusal özerk yönetimi oluşturması da engellenmiştir. Bkz: A. Füsun Beşler (Arsava), a.g.e., s. 89 vd.

30 Federal devlet düzeninde demokratik çoğunluk prensibi küçük ulusal grubun himayesi adına sınırlıdır. Federal devlette birliğin çıkarları korunduğu gibi, ulusal grupların çıkarları da korunur. Ulusal grupların çıkarları federe organlarda karara bağlanır. Bir ulusal gruba ait hakların sinırlanması yahut ortadan kaldınlması federal devlette ancak , anayasa değişikliği ile gerçekleşebilir.

Bugü insan topluluklarının varacağı son hedef olarak ulusal devletler görülmemektedir; bu nedenle federel devlet, ulusal yaşam ve müşterek yaklaşımı en iyi şekilde harmonize eden bir rejim olarak kabul edilmektedir.

31M. Tamkoç. The Turkish Cypriot State. The Embodiment of the Right of Selfdetermination, Texas Tech University, 1988. 
otoriteye karşı rahatlıkla kullanılabilir ${ }^{32}$. Bugün Kıbrıs'ta selfdetermination hakkı iki ayn topluma, Kıbrıs Türk ve Kıbrıs Rum topluluğuna geçmiştir. Ayrı ayn kullanılan selfdetermination hakkına istinaden kuzeyde bütün unsunları ile bir bağımsız devlet, güneyde de ayrı bir devlet ortaya çıkmışur.

Kıbrıs türklerinin selfdetermination hakkını reddederken, tüm Kıbrıs adına bu hakkı kullanma iddiası ile Güney Kıbrıs Rum yönetiminin AB'ne tam üyelik başvurusu yapması, AB'nin de başvuruyu gündemine alıp, Kıbrıs Rum Yönetimini hükümetler arası konferans için Torino'ya davet etmesi, Kıbrıs Rum topluluğunun şimdiye dek yol açtığı Uluslararası Hukuk ihlallerinin gözardı edilmesi, bu ihlallere meşruiyet kazandırılması anlamını taşı ${ }^{33}$. 1960'da kurulan Kıbrıs Cumhuriyeti devletinin anayasanın ihlali ve Garanti anlaşmašnın ihlali ile sonunu hazırlayan Kıbrıs Rum tarafıdır. Kendilerinin sonunu hazıladıklan devletin mevcudiyetinin devamı iddiasını, anayasanın kendi çıkarları doğrultusunda tek taraflı revizyonu ve Garanti anlaşmasının bir kenara itilmesi gerçeği ile paralel değerlendirmek gerekir. 1960'da Kıbrıs'ta yaratılan sistem bir bütünlük içinde; ulusal ve uluslararası uzlaşı sağlanarak yürürlüğe konulmuştur. Sistemin tck taraflı olarak revize edilmesi kurulan dengelerin bozulması sonucunu doğurur ${ }^{34}$.

Kuzey Kıbrıs Türk devleti, bir devleti oluşturan, insan topluluğu, ülke, egemenlik yetkileri ve tüm kuramsal yapısı ile uluslararası camiada yer almaktadır. Uluslararası Hukuk "tanımayı" bugün devleti oluşturan asli bir unsur olarak görmemektedir ${ }^{35}$. Tanıma Uluslararası Hukuka göre uluslararası camiaya katılmanın saptanması anlamını taşır. Oysa bir devletin oluşumu tarihi ve siyasi bir olgudur. Uluslararası Hukuk işte sadece bu olgunun saptanması yetkisini "tanıma işlemi" ile uluslararası camianın mevcut devletlerine tanımaktadır. Bir devlet siyasi ve tarihi bir olgu olarak mevcut ise, onun tanınmaması onun devlet olma niteliğini ortadan kaldırmamaktadır. Bir çocuk doğmuştur. Onun tanınmaması onun Uluslararası Hukuk sujesi olma ehliyetini ortadan kaldıran sonuç doğurmaz; bu nedenle Kıbrıs Türk toplumunun iradesi dikkate alınmaksızın Kıbrıs'ta bir çözümün bulunması imkansızdır. Kıbrıs ikiye bölünmüştür. Iki devletin egemenlik alanlan ayrılmışur. Iki bölge, iki devlet ortaya çıkmışur. Çözümün bu gerçek üzerine inşa edilmesi gerekmektedir.

Federasyon, ikiye bölünen Kıbrıs'ı bir çau alunda birleştiren bir formül olabilir. Kıbns Rum yönetimi ülkenin ve egemenliğin birliğini teminat altına alacak eski üniter devlet modeli üzerinde durmakla beraber, her iki devletin ayrı Uluslararası Hukuk sujeliğini teyit edecek konfederasyon modelinc nazaran tek bir uluslararası hukuk sujeliğini kabul eden federasyon modelini de gündemde tutmaktadır. Kıbrıs Türkleri Rumlarla yeni bir ortaklık anlaşması yapıp yapmama kararını Kıbrıs Rumlarının gösterecekleri iyi niyet ve anlayı̧̧ içinde verecektir. Kıbrıs Türklerinin Kıbrıs Rumlarıyla

32 A. Füsun Arsava, Azınlık Kavramı ve Azınlık Haklarının Uluslararası Belgeler ve özellikle Medeni ve Siyasi Haklar Sözleşmesinin 27. maddesi ışı̆̆ında incelenmesi, Ankara 1993, s. 121.

${ }^{33}$ E. Lauterpacht. Turkish Republic of Northern Cyprus, The Status of the two Communities in Cyprus, 1190.

341969 tarihli Viyana anlaşmaları Hukuk sözleş̧mesi, çok taraflı bir anlaşmanın tek tarafl olarak değiştirilmesini, aşkıya alınmasını yahut sona erdirilmesini reddetmektedir. Madde 54, madde 57.

35 Bkz.: Dahm/Delbrück/Wolfrum, Völkerrecht, Berlin 1988. 
yapacağı ortaklığın hiçbir zaman "meşru Kıbrıs yönetimine" entegre olma anlamında yorumlanması mümkün değildir.

Kıbrıs Türk vè Rum toplumu ayrı ayrı selfdetermination hakkı olan, siyasi açıdan eşit ve egemen iki toplumdur. Federal bir Kıbrıs devletinin teminatı yine 1960 Garanti anlaşması olmak zorundadır. Kıbrıs Rum yönetimi ile bir federasyon anlaşması yapılacaksa Kıbrıs Türk toplumunun selfdetermination hakkını birkez daha kullanarak, federasyona iştirak edip etmeme konusunda iradesini ortaya koyması gerekmektedir.

Uluslararası camianın Kıbrıs Rum yönetimine "meşru Kıbrıs hükümeti" muamelesi yapmaya devam cttikçe Rum tarafının stratejisini değiştirmesini beklemek iyimserlik olur. Barışa yardımcı olma sorumluluğu olan uluslararası camiaya bu çerçevede düşen görev, 1960 Kıbrıs Cumhuriyeti Devletinin 1963 ve devamında cereyan eden ulusal ve Uluslararası Hukuk ihlalleri nedeniyle ikiye bölündüğünü ve her iki tarafın kendi kesiminde, diğerine denk egemenlik yetkilerine sahip devlet olduğunu, selfdetermination hakkının her iki topluma ayrı ayn geçtiğini kavrayıp, Kıbrıs Rum yönetimine ulusal ve uluslararası dengelerin yeniden kurulması koşuluyla adada bir çözüme ulaşılabilcceğini anlatması gerekir ${ }^{36}$. Kıbrıs'ın tümüne sahip olma iddiası ile Kıbrıs Türkünün selfdetermination hakkını reddetmek çözüm değil, çözümsüzlüğ̈ün devamina neden olur.

Kıbrıs sorunı Kıbrıs Rum yönetiminin tüm Kıbns üzerinde iddiasını sürdürdükçe, meşru hükümetin sadece kendisi olduğunu iddia ettikçe çözülemez. Çözüm ya bugünkü status quo'nun kabul edilmesi ile ya da iki tarafın ortak iradesi ile federal devlet çatısı altında birleşerek bulunabilir ${ }^{37}$. Kıbris Rum yönetiminin kendi çıkarlarına görc 1960 'da kurulan devletin varlığının devamını, ancak onun varlığına esas olan sistemi bir kenara iterek, iddia etmesi kabul edilemez. Sistem ya bütünüyle geçerlidir ya da geçersizdir. 1960 'da kurulan sistem geçerli ise Kıbrıs Rum yönetiminin Avrupa Birliği'ne tam üyelik başvurusunun ${ }^{38}$ Garanti anlaşmasının teminatı altında olan anayasanın 50 . maddesini gözönünde tutarak değerlendirilmesi gerekir. Anayasanın 50. maddesi, Kıbrıs'ın sadece Türkiye ve Yunanistan'ın üye olduğu uluslararası kuruluşlara. katılmasını mümkün görmektedir. Avrupa Birliğine Yunanistan tam üyedir, ancak Türkiye henüz tam üye değildir. Kıbrıs Rum yönetimi elbette başvurusunu adada yer alan bağımsız, ayrı bir devlet olarak yapmış olabilir. Ancak bu başvuru ve sonuçlar sadece Güncy Kıbrıs devleti ile sinırlı olmak durumundadır.

Bu sonuç adadaki status quo'nun bir çözüm olarak benimsenmesi anlamını taşır. Böyle bir çözüm yeni çözümsüzlüklere yol açabilecek bir modele tercih edilmclidir. Kıbris Türk toplumu ve Kıbris Rum toplumu 1960. yılında kurulan üniter bir devlet yapısı içinde en etkin teminata, düzenlemelere rağmen uzlaşamadı. Bu uzlaşmazlığın bir federal devlet modeli içinde giderilebilmesi, Kıbns Rum toplumunun hakim ulus olma iddiasından vazgeçmesinin bir ütopya olması nedeniyle, ancak bir düş olabilir.

${ }^{36} \mathrm{C}$. Heinze, "Der Zypernkoflikt, eine Bewachrungsprobe westlicher Friedensordnung", Europa Archiv, 10 (1964), s. 713, 726; R. Denktaş, Kıbris'ta Bitmeyen Kavga. Kök, Sosyal ve Stratejik Araştırmalar Servisi: 8, Ankara, 1991.

37 A. Füsun Beşler (Arsava), a.g.e., s. 98 vd.

38 Neue Zürcher Zeitung, Fernausgabe vom 7 Juli 1990; Süddeutsche Zeitung Nr. 236 vom $13 / 14$ Oktober 1990 , s. 10. 